evidence of the substantial contribution which has been made to our knowledge of the world flora. Such an authoritative list of the names of plants, giving the author and place of publication of each, together with reference to synonymy and geographical distribution, is indispensable to all workers on the taxonomy of flowering plants.

An additional feature which distinguishes this from earlier Supplements is the insertion of an asterisk against those entries where an illustration accom. panies the deseription of the new species. In this simple way the "Index Kewensis" will continue the function of the "Index Londonensis", a work which was brought to a conclusion in 1941 .

J. R. Matphews

\section{ENCYCLOPADIA OF EYES}

\section{Tabulæ Biologicæ}

Vol. 22: Oculus, Pars 1. Editores : K. Steindorff, F. P. Fischer, J. S. Friedenwald, Arnold Sorsby. Pp. viii + 408. (Amsterdam : Dr. W. Junk, 1947.) 70 fl.

$\mathrm{O}$ $\mathrm{NE}$ of the functions of science is to collect information and to classify it. Some of the information so collected may appear to any one person to be trivial or of little importance, but let that person remember that he is not the only oyster in the bed, and he will realize that the sand grains around him may become pearls for others. To one interested in the activities of the human eye there may seem to be little significance in measurements which relate the width of the ocellus of an ant to the breadth of its head; but to another, interested in the behaviour of ants, this information may be of far more value than statistics on the occurrence of blondes in Austria, or the relation between intraocular pressure and the thymus gland. The first part of "Oculus" contains collected numerical data on the structure and anatomy of eyes of all types, on the behaviour of the pupil and on vascular pressures in the eye; and the reader will find a wide diversity of subject-matter, including such topies as those mentioned above. The net is cast wide and the information collected is vast and various. Three further parts of the book are to follow, so that almost every aspect of the eye will be dealt with, each by a different author.

The task of collecting the data and preparing it for publication was largely undertaken or inspired by the late Kurt Steindorff, who clearly saw the advantages to be gained by collecting together as much information as possible in order to assist in elucidating the mysteries of vision. He might be described as the oculomotor nucleus.

In such a subject as vision, upon which the relevant literature is immense and still rapidly growing, it is easy to be critical on the grounds that such and such a table is not included in this volume; but since most of us who work on vision have experienced the mixed thrill and disappointment of finding that our much cherished ideas were either suggested or carried out in the last century, such criticism necessarily loses much of its force. Nevertheless, on such matters as the structure and distribution of the retinal constituents it is disappointing, for example, to find no references to the data collected by Polyak or Osterberg. There has clearly been some inevitable delay in the publication of the volume, and thus many of the more recently derived data are not included.
Moreover, the index is to appear in a later volume and the bibliographies are arranged numerically, more or less in order of appearance in the text, and not alphabetically according to authors, so that it is difficult to be certain that one does not miss information through searching for it in the wrong place. Such difficulties will, of course, vanish when the whole work is published, and, when this occurs, ophthalmologists of all types will have an extremely valuable compendium of information.

E. N. WILLMER

\section{VEGETABLE GROWING}

\section{Vegetable Growing}

By Prof. James Sheldon Shoemaker. Pp. v +506 . (New York: John Wiley and Sons, Inc.; London : Chapman and Hall, Ltd., 1947.) 27s. net.

T is unusual to find a North American book on any aspect of practical horticulture which is of much direct value in Great Britain. Prof. J. S. Shoemaker, perhaps because he is primarily a man of science, has produced a book which is an exception to the rule. The reason lies in the method of approach to the subject, which is more through the requirements of the crop than its detailed culture. While it is true that much of the discussion on varieties has little application in Britain, yet, because of the closer horticultural links of Canada with the home country, many more English varieties are included than one would find in a book from the United States.

Because of the prime importance of good seed in successful vegetable cultivation, the book starts with a discussion on seed production. This is undoubtedly a most valuable section, since few books on vegetables give more than cursory attention to the subject. The major part of the work is devoted to the specific crops, grouped aceording to use ; for example, corn crops, root crops, salad crops, etc. The traditional procedure of giving preliminary chapters on soils, fertilizers and other considerations has been abandoned in favour of discussing these problems in relation to each crop, thus enabling direct application of research findings to be presented in their proper context. It is this treatment which lifts the book out of the general run of gardening manuals and raises it to scientific levels.

A surprising omission, however, in a book of this high standard is that of scientific names and botanical characteristics. The history of each vegetable is most admirably summarized, but to the serious student the interest and value would be greatly enhanced by reference to the botany of the crop. This is particularly true of the last chapter, on insect and disease control. Of what value to a student, especially in another country, is a reference to "early blight" and "late blight" of celery unless he knows that these are due to two different fungi, Cercospora apii and Septoria apii? Again, what is one to understand by "haywire", "calico" and "jelly-end rot" of potatoes? Even where the genus of an insect or a fungus is mentioned or elearly obvious, addition of the specific name would avoid confusion with other species possibly more common in another country. Perhaps in a second edition the author will bear in mind the needs of workers and students in Britain and elsewhere.

R. H. Stoughton 